\title{
Problematic smartphone use and affective temperaments among Lebanese young adults: scale validation and mediating role of self-esteem
}

Joanne Zeidan' ${ }^{1}$ Souheil Hallit ${ }^{2,6^{*}}$, Marwan Akel ${ }^{3,4}$, Ismail Louragli5 and Sahar Obeid ${ }^{1,3}$

\begin{abstract}
Background: Adults all over the world face serious issues from problematic smartphone use (PSU). It influences them negatively on a cognitive, behavioral, and emotional level, as well as on their tendencies and well-being. In Lebanon, the prevalence of PSU was shown to be $20.2 \%$ within the adult population, specifically with young adults (18-34 years old). This study investigates the validity and reliability of the Smartphone Addiction Scale (SAS) Arabic version. In addition, this study evaluates the association between PSU and affective temperaments and the mediating role of self-esteem in this association.
\end{abstract}

Method: A cross-sectional study was carried out between August and September 2020, using a sample of community-dwelling participants aged 18 to 29 years. The Smartphone Addiction Scale-Short Version was used to evaluate smartphone addiction among adolescents and adults. The five different temperaments of the patients were assessed by using the Affective temperament Scale (TEMPS-A). The Rosenberg Self-Esteem Scale was used to evaluate self-esteem.

Results: 461 participants were included in this study. All items of the SAS were extracted and yielded a one-factor solution with Eigenvalues $>1$ (variance explained $=49.96 \%$; $a_{\text {Cronbach }}=0.886$ ). The confirmatory analysis results consolidated those obtained from the factor analysis. Higher depressive temperament $(B=0.46)$ was significantly associated with more smartphone addiction, whereas higher self-esteem $(B=-0.28)$ was significantly associated with less smartphone addiction. Self-esteem was found to mediate the association between depressive and hyperthymic temperaments with smartphone addiction.

Conclusion: This study added a better understanding of the high smartphone addiction rate among adults in Lebanon. It confirms the association between affective temperaments and PSU through the mediating effect of selfesteem on Lebanese adults.

Keywords: Problematic use of smartphones, Self-esteem, Affective temperaments, Lebanese adults, Smartphone addiction

*Correspondence: souheilhallit@hotmail.com

2 Faculty of Medicine and Medical Sciences, Holy Spirit University of Kaslik (USEK), Jounieh, Lebanon

Full list of author information is available at the end of the article

\section{Background}

A smartphone is "a device that combines a cell phone with a handheld computer, typically offering internet access, data storage, email capability, etc." [1]. In the past few years, recent research explored the 
relationship that develops between the user and his smartphone [2-5]. Despite providing many advantages in improving the user's everyday life, studies have shown that, in some situations, smartphones present association with patterns of behavioral addiction that lead to negative consequences $[3,8,9]$. Behavioral addiction is defined as "a repetitive habit pattern that increases the risk of disease and/or associated personal and social problems" [6]. In fact, previous studies have shown many examples of problematic use of smartphones leading to decrease of productivity, compromise of interactions with others, or mental illness [7-11], memory problems [12], alcohol use disorder [10, 13, 14], loneliness [15], alexithymia [16], etc.). To add, restriction from phone interaction in young adults can lead to performance impairment during a cognitive task and severe increases in levels of stress and anxiety [17-21].

Many studies use the term "smartphone addiction" based on the commonalities observed between excessive smartphone users and substance abusers such as losing control or seeking treatment $[20,21]$. However, there is little to no evidence to this day that a problematic use of smartphone could in fact be considered as an addiction since factors like tolerance and withdrawal syndrome are yet to be explored in this matter [22]. To avoid overpathologizing, the term problematic smartphone use (PSU) is commonly used [23]. Billieux et al. developed a definition for PSU as "an inability to regulate one's use of the smartphone, which eventually involves negative consequences in daily life" creating problems on social, psychological and behavioral levels [22-24]. The notion of PSU has its origins from two related notions. The first concept is that of the "problematic mobile phone use" introduced in recent research [25-27], especially before the revolutionary introduction of the smartphone in the market $[9,28,29]$. The second concept is the "problematic internet use" also known as "internet addiction" that helped in developing theories and methodologies for research work concerning PSU [30-32]. It is also worth mentioning that PSU is not acknowledged as a clinical form of addiction by the Diagnostic and Statistical Manual for Mental Disorders (DSM-5) and that it is, currently, still being debated about whether or not it should be recognized as such [33].

Adults all over the world face serious issues from PSU. It influences them negatively on a cognitive, behavioral, emotional level, and well-being [34]. PSU also constitutes a significant risk factor to people who are depressed or feeling lonely, anxious, and suffer from disturbance in their sleeping patterns [35]. To add, PSU may also cause problems in interpersonal relations and disturbances in academic performance [36-39].
The screening of PSU is performed using the short version of the Smartphone Addiction Scale (SAS-SV). The SAS is indeed a modern scale used to evaluate PSU validated amongst adolescents and young adults [40-45]. It was first developed in Korean language before being published in English [41]. The SAS-SV is one of the most validly used scales that is translated in different languages such as in Turkish [46], Spanish [47], French [47], Italian [43], Chinese [42] and Arabic [44, 48]. Despite its validated translation in Arabic in both Morocco [44] and Egypt [48], no psychometric validation of this scale has been carried out in Lebanon.

On that note, research found that people suffering from mood disorders are very prone to develop PSU [49]. Odegaard et al. [50] showed that in the early phases of major depressive disorders and bipolar disorders, early development of mood disorders is also affirmed by the presence of an affective temperament. This brings us to look into the association between PSU and affective temperaments. In fact, temperaments are unique characteristics of one's personality, which do not generally change with time [51]. Many studies contributed into developing these five main affective temperaments: depressive, cyclothymic, hyperthymic, irritable and anxious [51, 52]. Previous research has shown that there is a relation between addiction to the Internet and all five affective temperaments, particularly with the anxious temperament [53].

While one of the factors involved in the development of PSU is affective temperaments, other studies link these two variables to self-esteem. One study highlighted the relationship between affective temperaments and selfesteem by showing the positive correlation between a high level of self-esteem and cyclothymic and anxious temperament [54]. Moreover, another research suggested sub-factors to each of the five affective temperaments and placed low self-esteem as a sub-factor to the depressive temperament while high self-esteem was placed as a sub-factor of the hyperthymic temperament [55]. Furthermore, other studies found that self-esteem is a risk factor and an antecedent of PSU $[24,56,57]$.

In Lebanon, the prevalence of PSU was shown to be $20.2 \%$ with $95 \%$ CI $[14.7,25.7]$ within the adult population, specifically with young adults (18-34 years old) who are single and have access to mobile internet services [58]. In fact, since the fall of 2019, Lebanon saw the rise of an economic crisis as a consequence of poor political governance after the civil war. This caused different issues with the supply chains and decreased the Lebanese currency value vis-à-vis the US dollars. Lebanon suffered limitations on transferring money outside the country because of capital control done illegally [59]. Hence, unemployment rates grew with huge loss of purchasing 
capacity [60]. To add, the COVID-19 outbreak did not make things easier on the Lebanese population facing this hard economic crisis. A recent Lebanese study showed that fear created from the COVID-19 pandemic combined with the very difficult financial situation in the country was associated with high levels of stress and anxiety [61]. Another study done in Lebanon showed in fact that depression and anxiety are factors associated with PSU [62].

As we see, exploring PSU with an etiological intent can give us crucial results that could be used in order to diminish the negative consequences of PSU amongst Lebanese young adults. Even though research showed a relationship between affective temperaments and PSU, very little to no research backs up the underlying mechanism of this dynamic. Thus, the importance of clarifying the nature of this relationship lies in bringing a better understanding of the mediating effect that self-esteem has between affective temperaments and the development of PSU. While no previous studies have worked on the relationship between these three variables and of selfesteem as a mediating factor, this study investigates the reliability and validity of the Arabic version of the Smartphone Addiction Scale. Also, this study evaluates the association between PSU and affective temperaments, as well as the mediating effect of self-esteem.

\section{Methods}

\section{Study design}

A cross-sectional study was carried out between August and September 2020, during the lockdown period imposed by the government for the COVID-19 pandemic which coincides with the summer season vacation for most Lebanese. A sample of community-dwelling participants aged 18 to 29 years was used [63]. All methods were performed in accordance with the relevant guidelines and regulations.

\section{Participants}

Due to the imposed COVID-19 restrictions, a survey was created using Google forms in order to mitigate the risky face-to-face interactions. The survey was shared among the participants and sent to all districts/governorates of Lebanon (Beirut, Mount Lebanon, North Lebanon, South Lebanon, and Bekaa) using the snowball technique; participants were asked to fill the survey online and share the link with other acquaintances and family members. All participants above 18 and below 30 years of age who had a mobile phone, were eligible to participate. Excluded were those who refused to fill out the questionnaire. Participants were not compensated for participation. A total of 461 persons participated in the study. Their mean age was $22.25 \pm 2.87$ years, with $70.9 \%$ females. Almost all the participants were single (91.3\%) and have a university education level (94.4\%). The mean household crowding index was $1.08 \pm 0.61$ (Table 1 ).

\section{Minimal sample size calculation}

According to the G-power software, and based on an effect size $\mathrm{f} 2=2 \%$, an alpha error of $5 \%$, a power of $80 \%$, and taking into consideration 10 factors to be entered in the multivariable analysis, the results showed that a minimal number of 395 was needed.

\section{Translation procedure}

The scales were forward and back-translated. Forward translation (English to Arabic) was performed by one translator, whereas the back translation from Arabic to English was performed by a second translator. Minor discrepancies were solved by consensus.

\section{Questionnaire and variables}

The self-administered questionnaire with closed-ended questions was anonymous and available in Arabic and English; the questionnaire required approximately 25-30 min to be completed. The questionnaire consisted of different sections. The first part clarified socio-demographic characteristics: age, gender, marital status, work status, educational level, and household crowding index. The latter was calculated by dividing the number of persons in the house by the number of rooms in the house (excluding the bathrooms and kitchen); higher scores reflect lower socioeconomic status [64]. The second part of the questionnaire included the following scales:

\section{Smartphone addiction scale-short version (SAS-SV)}

The SAS-SV is a ten-item scale used to evaluate smartphone addiction among adolescents and adults [41, 42].

Table 1 Sociodemographic characteristics of the study sample $(\mathrm{N}=461)$

\begin{tabular}{ll}
\hline & Frequency (\%) \\
\hline Gender & \\
Male & $134(29.1 \%)$ \\
Female & $327(70.9 \%)$ \\
Marital status & \\
Single/widowed/divorced & $421(91.3 \%)$ \\
Married & $40(8.7 \%)$ \\
Education level & \\
School education & $26(5.6 \%)$ \\
University education & $435(94.4 \%)$ \\
\hline & Mean \pm SD \\
\hline Age (in years) & $22.25 \pm 2.87$ \\
Household crowding index & $1.08 \pm 0.61$ \\
\hline
\end{tabular}


Table 2 Coefficient, standard error and $p$-value of the confirmatory factor analysis of the SAS scale items

\begin{tabular}{|c|c|c|c|}
\hline Variable & Coefficient & Standard error & $p$ \\
\hline 1. Missing planned work due to smartphone use & 1 & & \\
\hline $\begin{array}{l}\text { 2. Having a hard time concentrating in class, while doing assignments, or while working due to smartphone } \\
\text { use }\end{array}$ & 0.650 & 0.951 & $<0.001$ \\
\hline 3. Feeling pain in the wrists or at the back of the neck while using a smartphone & 0.478 & 0.741 & $<0.001$ \\
\hline 4. Won't be able to stand not having a smartphone & 0.691 & 1.131 & $<0.001$ \\
\hline 5. Feeling impatient and fretful when I am not holding my smartphone & 0.707 & 1.043 & $<0.001$ \\
\hline 6. Having my smartphone in my mind even when I am not using it & 0.519 & 0.751 & $<0.001$ \\
\hline 7. I will never give up using my smartphone even when my daily life is already greatly affected by it & 0.689 & 1.072 & $<0.001$ \\
\hline $\begin{array}{l}\text { 8. Constantly checking my smartphone so as not to miss conversations between other people on Twitter or } \\
\text { Facebook }\end{array}$ & 0.696 & 0.994 & $<0.001$ \\
\hline 9. Using my smartphone longer than I had intended & 0.792 & 1.178 & $<0.001$ \\
\hline 10. The people around me tell me that I use my smartphone too much & 0.762 & 1.077 & $<0.001$ \\
\hline
\end{tabular}

The total score was computed by adding the answers of these 10 items, with higher scores reflecting higher smartphone addiction. In this study, the SAS Cronbach's alpha value was 0.886 .

\section{Affective temperament scale (TEMPS-M)}

Affective temperament traits were assessed by means of the brief version of the Temperament Evaluation of Memphis, Pisa, Paris, and San Diego (TEMPS-M) [65]. This scale is composed of 35 self-rating items that can be assigned to 5 subscales: depressive, cyclothymic, hyperthymic, irritable, and anxious. All responses are provided on 6-point Likert scales ranging from 1 (not at all) to 5 (very much). Each subscale score ranges from 5 to 35, with higher scores denoting higher expressions of the respective temperament. The Cronbach's alpha values for each subscale were as follows: depressive (0.809), cyclothymic (0.898), hyperthymic (0.818), irritable (0.808), and anxious (0.856).

\section{Rosenberg self-esteem scale}

The Rosenberg Self-Esteem Scale (RSES) is a 10-item scale that reflects self-worth by focusing on both positive and negative feelings people have about themselves [66]. Responses were scored from 1, meaning strongly disagree, to 4 , meaning strongly agree, where higher scores reflect a better self-esteem (Cronbach's alpha in this study 0.837).

\section{Statistical analysis}

Data analysis was conducted using SPSS software v.23 and SPSS AMOS v.24 was used to conduct the confirmatory factor analysis. The latter was conducted based on the one-factor solution of the SAS items obtained in the original of the scale $[41,42]$. The goodness-of-fit of the model was evaluated by calculating the root mean square error of approximation (RMSEA) statistic and the comparative fit index (CFI) as these are the most commonly used indices [67]. Values of RMSEA $<0.05$ and $<0.11$ indicate a close fit and an acceptable fit, respectively [68]. CFI values $>0.90$ indicate a relatively good fit of the model [67].

Normal distribution of the SAS score was confirmed after calculating skewness and kurtosis; a range of value between -2 and +2 for asymmetry and kurtosis is adopted in order to prove normal univariate distribution [69]. These conditions consolidate the assumptions of normality in samples larger than 300 [70]. Student's t-test was used to compare mean smartphone addiction differences between gender, marital status and education level respectively, whereas Pearson correlation coefficient was obtained to check for any correlation between two continuous variables (e.g. smartphone addiction and each temperament). A forward linear regression was conducted to check for correlates associated with smartphone addiction.

\section{Mediation analysis}

The PROCESS SPSS Macro version 3.4, model four was used to calculate three pathways [71]. Pathway A determined the regression coefficient for the effect of each temperament on self-esteem. Pathway B examined the effect of self-esteem on smartphone addiction independent of temperament. Pathway $\mathrm{C}$ estimated the total and direct effect of each temperament on smartphone addiction and pathway $\mathrm{AB}$ calculated the indirect intervention effects. A 95\% CI was used to assess for indirect effect significance [71]. Independent variables with a value of $p<0.2$ in the bivariate analysis were included in the multivariable and mediation models. Cronbach's alpha values were recorded for reliability analysis of all scales and subscales. Statistical significance was set at a $p<0.05$. 
Table 3 Bivariate analysis taking the smartphone addiction scale as the dependent variable

\begin{tabular}{|c|c|c|}
\hline & Smartphone addiction & $p$ \\
\hline & Mean $\pm S D$ & \\
\hline \multicolumn{3}{|l|}{ Gender } \\
\hline Male & $31.06 \pm 9.46$ & 0.838 \\
\hline Female & $31.24 \pm 8.54$ & \\
\hline \multicolumn{3}{|l|}{ Marital status } \\
\hline Single & $31.35 \pm 8.82$ & 0.198 \\
\hline Married & $29.47 \pm 8.58$ & \\
\hline \multicolumn{3}{|l|}{ Education level } \\
\hline School education & $31.73 \pm 9.29$ & 0.748 \\
\hline \multirow[t]{2}{*}{ University education } & $31.16 \pm 8.79$ & \\
\hline & Correlation coefficient & \\
\hline Depressive temperament & 0.358 & $<0.001$ \\
\hline Cyclothymic temperament & 0.330 & $<0.001$ \\
\hline Hyperthymic temperament & 0.091 & 0.051 \\
\hline Irritable temperament & 0.227 & $<0.001$ \\
\hline Anxious temperament & 0.272 & $<0.001$ \\
\hline Self-esteem scale & -0.286 & $<0.001$ \\
\hline Age & -0.052 & 0.266 \\
\hline Household crowding index & -0.106 & 0.023 \\
\hline Number of children & 0.012 & 0.804 \\
\hline
\end{tabular}

Numbers in bold indicate significant $p$-values

Table 4 Multivariable analysis: Linear regression considering the smartphone addiction score as the dependent variable

\begin{tabular}{|c|c|c|c|c|c|}
\hline Variable & $\begin{array}{l}\text { Unstandardized } \\
\text { beta }\end{array}$ & $\begin{array}{l}\text { Standardized } \\
\text { beta }\end{array}$ & $p$ & $\begin{array}{l}95 \% \\
\text { Confi } \\
\text { interv }\end{array}$ & $\begin{array}{l}\text { lence } \\
\text { al }\end{array}$ \\
\hline $\begin{array}{l}\text { Depressive } \\
\text { temperament }\end{array}$ & 0.46 & 0.29 & $<0.001$ & 0.31 & 0.61 \\
\hline Self-esteem & -0.28 & -0.17 & $<0.001$ & -0.43 & -0.13 \\
\hline
\end{tabular}

Variables entered in the models: marital status, age, gender, household crowding index, depressive temperament, cyclothymic temperament, hyperthymic temperament, irritable temperament, anxious temperament and self-esteem scale

Adjusted $\mathrm{R}^{2}=0.152, p<0.001$

Numbers in bold indicate significant $p$-values

\section{Results}

The means and standard deviations of the scales were as follows: smartphone addiction (31.19 \pm 8.80 ; median $=31)$, depressive temperament $(16.13 \pm 5.54)$, cyclothymic temperament $(18.30 \pm 6.94)$, hyperthymic temperament $(20.69 \pm 5.94)$, irritable temperament $(18.38 \pm 5.67)$, anxious temperament $(17.32 \pm 6.49)$, and self-esteem $(28.48 \pm 5.36)$.

\section{Confirmatory factor analysis}

Table 2 presents the coefficients with standard errors and $p$-values of the direct effects of variables on each other.
For this model, the estimated RMSEA is 0.09 with a confidence interval (0.082-0.109), which shows an acceptable fit, with a CFI value of 0.923 , which shows adequate fit.

\section{Bivariate analysis}

Higher depressive temperament $(r=0.358)$, cyclothymic temperament $(r=0.330)$, irritable temperament $(r=0.227)$, anxious temperament $(r=0.272)$ were significantly associated with more smartphone addiction, whereas higher self-esteem $(r=-0.286)$ and higher household crowding index $(r=-0.106)$ were significantly associated with less smartphone addiction (Table 3).

\section{Multivariable analysis}

The results of the linear regression, considering the smartphone addiction score as the dependent variable, showed that higher depressive temperament $(B=0.46)$ was significantly associated with more smartphone addiction, whereas higher self-esteem $(B=-0.28)$ was significantly associated with less smartphone addiction (Table 4).

\section{Mediation analysis}

The direct and indirect effects of the associations between each temperament, self-esteem and smartphone 
Table 5 Mediation analysis: Direct and indirect effects of the associations between each temperament, self-esteem and smartphone addiction

\begin{tabular}{|c|c|c|c|c|c|c|}
\hline \multirow[t]{2}{*}{ Temperament } & \multicolumn{3}{|c|}{ Direct effect } & \multicolumn{3}{|c|}{ Indirect effect } \\
\hline & Effect & SE & $p$ & Effect & SE & $95 \% \mathrm{BCa}$ \\
\hline Depressive & 0.210 & 0.132 & 0.112 & 0.126 & 0.055 & $0.027-0.242$ \\
\hline Cyclothymic & 0.144 & 0.102 & 0.157 & 0.053 & 0.025 & $0.010-0.110$ \\
\hline Hyperthymic & -0.072 & 0.104 & 0.491 & -0.155 & 0.061 & -0.279 to -0.039 \\
\hline Irritable & 0.119 & 0.107 & 0.270 & 0.0004 & 0.019 & $-0.042-0.038$ \\
\hline Anxious & 0.078 & 0.083 & 0.350 & -0.001 & 0.017 & $-0.003-0.004$ \\
\hline
\end{tabular}

Direct effect $=$ Effect of the temperament on smartphone addiction in the absence of the mediator (self-esteem); Indirect effect =Effect of the temperament on smartphone addiction in the presence of the mediator (self-esteem); SE =Standard Error; BCa = Bootstrap Confidence Interval
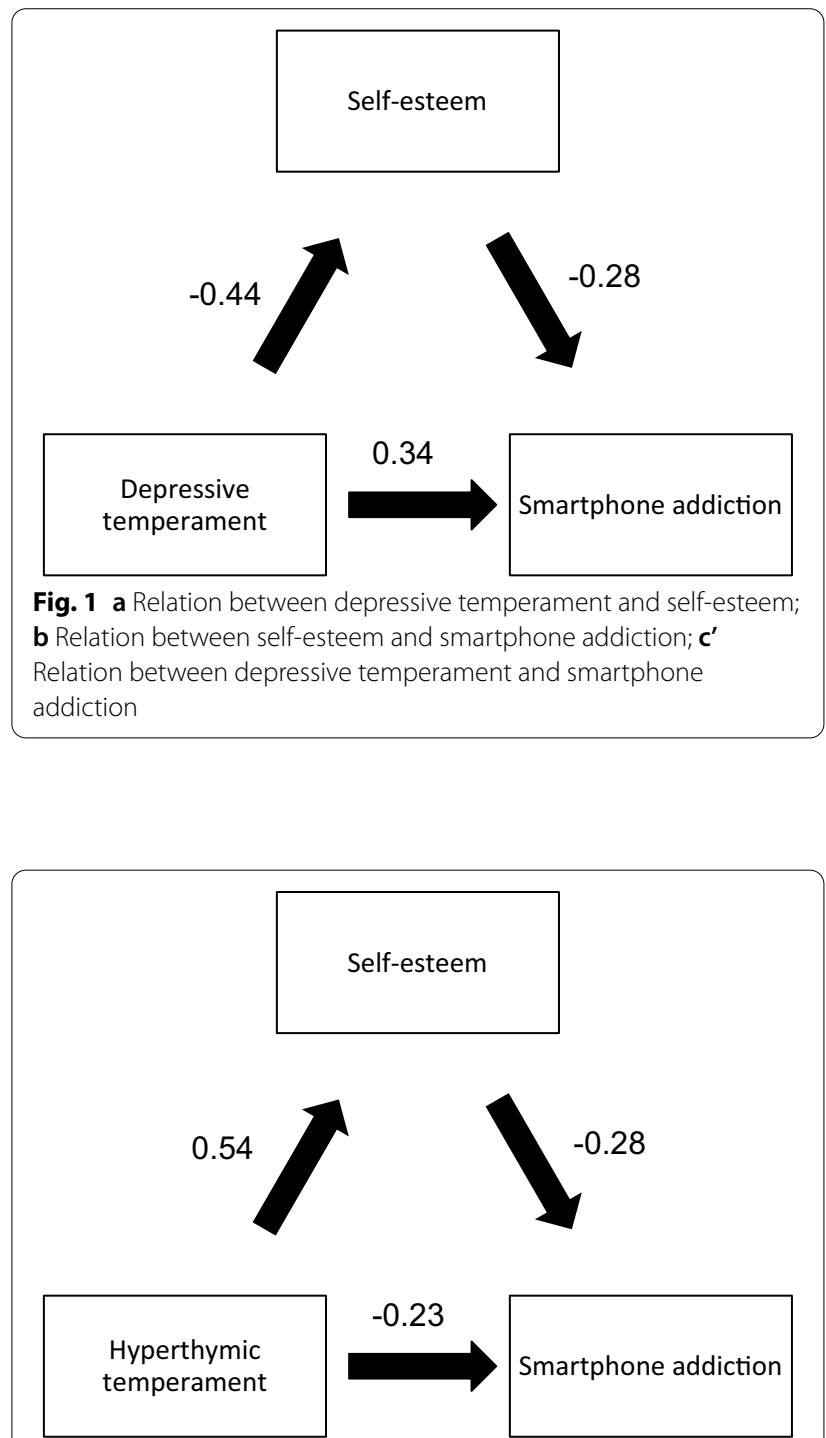

Fig. 2 a Relation between hyperthymic temperament and self-esteem; $\boldsymbol{b}$ Relation between self-esteem and smartphone addiction; $\mathbf{c}^{\prime}$ Relation between hyperthymic temperament and smartphone addiction addiction are summarized in Table 5 . The detailed results of the mediation analysis are summarized in Additional file 1: Table 1.

Depressive temperament was significantly associated with lower self-esteem and higher SAS score. When adding self-esteem to the model, depressive temperament did not show statistical significance with the SAS score, whereas higher self-esteem was significantly associated with lower SAS score (Fig. 1).

More hyperthymic temperament was significantly associated with higher self-esteem and lower SAS score. When adding self-esteem to the model, hyperthymic temperament did not show significance with the SAS score, whereas higher self-esteem was significantly associated with a lower SAS score (Fig. 2).

Self-esteem mediated the association between depressive temperament and smartphone addiction and between hyperthymic temperament and smartphone addiction.

\section{Discussion \\ Validation of smartphone addiction scale short version (SAS-SV) in Arabic language}

The confirmatory factor analysis results obtained in this study confirmed the one-factor solution of the SAS obtained in previous studies [41, 42]. The RMSEA value had an acceptable fit, whereas the CFI value suggested a good fitting model. The translated SAS-SV in this study was validated with a Cronbach's alpha coefficient of $(\alpha=0.886)$. According to other studies that validated SAS-SV in their Arabic language populations, a study conducted by Sfendla et al., 2018 [44] on a sample of 310 university students in the Moroccan population showed an alpha coefficient of Cronbach of $(\alpha=0.87)$, while another study by Elkholy et al., 2020 with 200 university students in Egyptian population obtained a Cronbach's alpha coefficient of $(\alpha=0.94)$ [72]. However, this study's reliability is higher than other studies such as those carried out by Andrade et al., 2020 in Brazilian version with 
( $\alpha=0.819$ ) [73] and Ching et al. 2020 in Malaise version with $(\alpha=0.80)$ [40]. Thus, the Arabic version of the Smartphone Addiction Scale is similar to the original version and is a reliable tool for Lebanese young adults.

\section{Temperaments, self-esteem and PSU}

The results of the linear regression, taking the smartphone addiction score as the dependent variable, showed that higher depressive temperament was significantly associated with more smartphone addiction. Ozturk et al. reported in their study that Internet addiction was highly associated with affective temperaments including the depressive temperament [53]. Indeed, affective temperaments, if dysregulated, could develop into abnormal affective pathologies that could emerge within mood disorders and affective disorders [74]. While the complexity of the relation between affective temperaments and mood episodes still prevails, research proved that there is an underlying role of a depressive temperament within unipolar major depression [74]. To add, researchers have shown that depression is a risk factor of PSU; when individuals are overwhelmed with negative emotions as a result of their depression, they have a tendency to rely on their smartphones as an escape strategy for the purpose of avoiding these negative emotions [18, 75, 76]. Nevertheless, PSU, as an escape strategy, has negative consequences since it does not give the outcome desired [77].

On the other hand, the findings of this study showed that higher self-esteem was significantly associated with a lower smartphone addiction rate. These findings support previous studies correlating low self-esteem with smartphone addiction [78] proving that self-esteem is a predictor of developing PSU $[24,56,57,79]$. Davis elaborated a cognitive-behavioral model showing that PSU is at the core of developing the maladaptive cognition of the self, including low self-esteem [80]. Indeed, individuals who suffer from low self-esteem believe that they are held in higher esteem by other individuals during online interactions. Therefore, they rely on this modality to seek approval and recognition. Moreover, Greenberg et al. [81] developed the terror management theory of selfesteem: when individuals face a threatening situation that intimidates their self-esteem integrity, they engage in compensatory behaviors, such as PSU or other behavioral problems. Through the smartphone vessel, they can reach a virtual world to satisfy their self-esteem. Nonetheless, this PSU could lead to a vicious cycle. Another caveat highlighted by Yea and Kim where individuals with low self-esteem were inclined towards virtual interactions instead of in-person interactions in order to seek reassurance [82]. Consequently, this smartphone dependence could lead to a PSU as a way to fulfill these needs $[24,83,84]$.

\section{Mediation analysis}

The results of the mediation analysis, taking self-esteem as a mediating variable, showed that self-esteem fully mediated the association between depressive temperament and smartphone addiction. To understand the mediating effect of self-esteem between the depressive temperament and PSU, self-esteem should be considered as a risk factor of PSU $[24,56,57]$. A previous study associated depressive temperament with self-esteem, suggesting low self-esteem as a sub-factor to the depressive temperament [55]. However, individuals with depressive temperament have been defined by many researchers as people who adopt a selfdenial mechanism to seek others' approval and recognition and find harmony in social conformity [85]. Once deprived from these social roles, they become vulnerable to developing clinical depression. These behaviors prevailing social norms can be defined as social desirability [86]. To draw the link between the depressive temperament and self-esteem, social desirability is considered to be a strategy of self-regulation, allowing the subject to preserve a fragile self-esteem [87]. Furthermore, the Social Desirability Scale predicts a fragile self-esteem and a dependency to seek approval from others [88]. Hence, social desirability found in depressive temperaments is considered a self-regulating strategy allowing the subject to preserve a fragile self-esteem by responding to assumed social expectations [89]. In addition, subjects that self-associated as the object of favorable evaluation by others, had a better self-esteem. In fact, selfesteem cannot be conceived of apart from the reference to a social group. This is why many researchers consider it to be, above all, a reflection of the popularity feeling and the need of others' approval: the level of self-esteem is highly correlated with the subjective experiences based on others' approvals or rejections [79] depending on the level of social conformity, a key trait in the depressive temperament. Hence, individuals with low self-esteem seek approval and recognition from other individuals they interact with in the virtual world through PSU [80]. To add, Ozturk et al. indicated that depressive temperament and addiction to the Internet are correlated [53]. Therefore, people with depressive temperament with high social desirability tend to preserve a fragile self-esteem by developing PSU to satisfy their need of belonging and obtaining recognition.

This study's results also showed that self-esteem fully mediated hyperthymic temperament and smartphone addiction. To understand the mediating effect of selfesteem between the hyperthymic temperament and PSU, Ozturk et al. [53] showed that hyperthymic temperament and addiction to the Internet are correlated. So far, one previous study associated hyperthymic temperament with 
self-esteem, suggesting high self-esteem was placed as a subfactor of the hyperthymic temperament [55], while another study showed a direct correlation between hyperthymic temperament and self-esteem amongst patients suffering from bipolar disorder [90]. Hyperthymic temperament is related to type A behavior pattern [91] involving a strong need to compete against other people because accomplishments are evaluated as more valuable than circumstances and rules [92]. In addition, hyperthymic temperament has been described as partially having reckless and selfish traits [93]. Karam et al. found that people with hyperthymic temperament would purposefully engage in conflicts with the people around them rather than agree with the opinion of the majority [94]. Although one of the traits of this temperament is "having self-confidence", other traits such as "liking to be the boss", "getting into heated arguments", and "the right and privilege to do as I please" reflect what Karam et al. called 'the dark side of the hyperthymic temperament' [94]. Indeed, from one side it protects the individual from suicidal behavior, but from the other side it corroborates the development of certain mental disorders. To draw the link between the dangerous effect of 'high self-esteem' as a trait of the hyperthymic temperament and PSU, studies have shown that a high level of self-esteem protects the person from developing PSU. However, subjects suffering from PSU tend to seek instant answers to preserve their selfesteem [95]. It could be noted that in order not to lose their high but fragile self-esteem, subjects with hyperthymic temperament develop PSU. Therefore, self-esteem has a mediating effect between hyperthymic temperament and PSU.

\section{Clinical implications}

This study could help experts, in a psychotherapeutic or psychological support setting, gain a better insight of the psychological functioning of the Lebanese adult population. When dealing with individuals with a high SAS score and / or problematic self-esteem level, therapists could refer to the findings in this study. As such, practitioners could help the subject improve identifying and prevent the negative implications of affective temperaments, problematic self-esteem and PSU while having a deeper knowledge of the mediating interrelations between these factors. When faced with a clinical demand to reduce PSU, therapeutic interventions on these specific temperaments could, therefore, focus on alleviating problematic self-esteem and thereby reduce the level of PSU.

\section{Limitations and strengths}

There are several limitations to this study that are worth mentioning to preserve the scientific integrity of this study and assist future research regarding this topic. The data's cross-sectional nature limits the ability to pull causal conclusions between our three variables. The use of a selfadministered questionnaire poses a risk for information bias since the answers can sometimes be random due to question misinterpretations. There is also a risk of selection bias, given the snowball sampling technique in this study. A residual confounding bias is possible since not all factors associated with problematic smartphone use were taken into consideration in this study. Nevertheless, in spite of these limitations, this research reported interesting results encouraging additional exploration of smartphone addiction, which is a significant issue in this population. These results can be extrapolated to the whole population according to the recruitment method followed. To end, in our review of literature and to our knowledge, we found no previous studies investigating the mediating effect of selfesteem between affective temperaments and PSU. This posed a challenge in comparing this study's results to those of previous studies, but on the other hand, it enhanced the importance and the uniqueness of this study.

\section{Conclusion}

To better understand the high smartphone addiction rate among young adults in Lebanon, this study uses a valid SAS to highlight the mediating self-esteem in the association between depressive and hyperthymic temperaments with problematic smartphone use. Future studies in other countries can yield comparative results that could also be useful in complementing this study. A cause and effect study could also be implemented to better understand the relationship dynamic between these three variables. Finally, studying different types of therapeutic interventions on affective temperaments may be beneficial in reducing the rate of PSU in Lebanese young adults. In fact, what matters most is not only depicting the associative factors behind PSU among adults in Lebanon, but also developing therapeutic plans and evaluating their efficiencies in the subject's growth towards a healthier mental health hygiene and optimal quality of life.

\section{Abbreviations}

SAS-SV: Smartphone addiction scale-short version; TEMPS-A: Affective temperament scale; RSES: Rosenberg self-esteem scale; PSU: Problematic social media use; DSM-5: Diagnostic and statistical manual for mental disorders.

\section{Supplementary Information}

The online version contains supplementary material available at https://doi. org/10.1186/s40359-021-00638-y.

Additional file 1. Full details of the mediation analysis taking self-esteem as a mediator between each temperament and smartphone addiction. 


\section{Acknowledgements}

The authors would like to thank all participants. Special thanks to Dr Aziz Saade for editing the paper. Special thanks to Pr. Pascale Salameh and Dr Hala Sacre for their help in preparing the study questionnaire.

\section{Authors' contributions}

SO and SH designed the study; JZ drafted the manuscript; SH carried out the analysis and interpreted the results; IL assisted in drafting and reviewing the manuscript; MA involved in the data collection; all authors reviewed and approved the final manuscript.

\section{Funding}

None.

\section{Availability of data and materials}

The datasets generated and/or analysed during the current study are not publicly available as per their institutions' policies but are available from the corresponding author on reasonable request.

\section{Declarations}

\section{Ethics approval and consent to participate}

The Psychiatric Hospital of the Cross Ethics and Research Committee approved the study protocol (HPC-033-2020). The purpose and requirements of the study were explained to each participant; A written informed consent was obtained from each participant; filling the form and submitting it online was equivalent to obtaining that consent.

\section{Consent for publication}

Not applicable.

\section{Competing interests}

The authors declare that they have no competing interests.

\section{Author details}

${ }^{1}$ Faculty of Arts and Sciences, Holy Spirit University of Kaslik (USEK), Jounieh, Lebanon. ${ }^{2}$ Faculty of Medicine and Medical Sciences, Holy Spirit University of Kaslik (USEK), Jounieh, Lebanon. ${ }^{3}$ INSPECT-LB: National Institute of Public Health, Clinical Epidemiology and Toxicology, Beirut, Lebanon. ${ }^{4}$ School of Pharmacy, Lebanese International University, Beirut, Lebanon. ${ }^{5}$ Ibn Tofail University, Kenitra, Morocco. ${ }^{6}$ Research Department, Psychiatric Hospital of the Cross, Jal Eddib, Lebanon.

\section{Received: 20 March 2021 Accepted: 14 August 2021}

Published online: 08 September 2021

\section{References}

1. Dictionary.com: The definition of smartphone. [online] (2015). http://dicti onary.reference.com/browse/smartphone. Accessed 07 February 2021.

2. Alter A. Irresistible: the rise of addictive technology and the business of keeping us hooked: Penguin; 2017.

3. Fullwood C, Quinn S, Kaye LK, Redding C. My virtual friend: a qualitative analysis of the attitudes and experiences of Smartphone users: implications for Smartphone attachment. Comput Hum Behav. 2017;75:347-55.

4. Melumad S, Inman JJ, Pham MT. Selectively emotional: how smartphone use changes user-generated content. J Mark Res. 2019;56(2):259-75.

5. Wilmer HH, Sherman LE, Chein JM. Smartphones and cognition: a review of research exploring the links between mobile technology habits and cognitive functioning. Front Psychol. 2017:8:605.

6. Marlatt GA, Baer JS, Donovan DM, Kivlahan DR. Addictive behaviors: etiology and treatment. Annu Rev Psychol. 1988;39(1):223-52

7. Farchakh Y, Hallit R, Akel M, Chalhoub C, Hachem M, Hallit S, Obeid S. Nomophobia in Lebanon: Scale validation and association with psychological aspects. PLoS One. 2021;16(4):e0249890. https://doi.org/10.1371/ journal.pone.0249890.

8. Malaeb D, Salameh P, Barbar S, Awad E, Haddad C, Hallit R, Sacre H, Akel M, Obeid S, Hallit S. Problematic social media use and mental health (depression, anxiety, and insomnia) among Lebanese adults: any mediating effect of stress? Perspect Psychiatr Care. 2021;57(2):539-49.

9. Bianchi A, Phillips JG. Psychological predictors of problem mobile phone use. Cyberpsychol Behav. 2005;8(1):39-51

10. Vahedi Z, Saiphoo A. The association between smartphone use, stress, and anxiety: a meta-analytic review. Stress Health. 2018;34(3):347-58.

11. Barbar S, Haddad C, Sacre H, Dagher D, Akel M, Kheir N, Salameh P, Hallit S, Obeid S. Factors associated with problematic social media use among a sample of Lebanese adults: the mediating role of emotional intelligence. Perspect Psychiatr Care. 2020.

12. Dagher M, Farchakh Y, Barbar S, Haddad C, Akel M, Hallit S, Obeid S. Association between problematic social media use and memory performance in a sample of Lebanese adults: the mediating effect of anxiety, depression, stress and insomnia. Head Face Med. 2021;17(1):6.

13. Dib JE, Haddad C, Sacre H, Akel M, Salameh P, Obeid S, Hallit S. Factors associated with problematic internet use among a large sample of Lebanese adolescents. BMC Pediatr. 2021;21(1):148

14. Obeid S, Saade S, Haddad C, Sacre H, Khansa W, Al Hajj R, Kheir N, Hallit S. Internet addiction among lebanese adolescents: the role of self-esteem, anger, depression, anxiety, social anxiety and fear, impulsivity, and aggression-a cross-sectional study. J Nerv Ment Dis. 2019;207(10):838-46.

15. Youssef L, Hallit R, Kheir N, Obeid S, Hallit S. Social media use disorder and loneliness: any association between the two? Results of a cross-sectional study among Lebanese adults. BMC Psychol. 2020;8(1):56.

16. Youssef $L$, Hallit R, Akel M, Kheir N, Obeid S, Hallit S. Social media use disorder and alexithymia: any association between the two? Results of a cross-sectional study among Lebanese adults. Perspect Psychiatr Care. 2021;57(1):20-6.

17. Hunter JF, Hooker ED, Rohleder N, Pressman SD. The use of smartphones as a digital security blanket: the influence of phone use and availability on psychological and physiological responses to social exclusion. Psychosom Med. 2018;80(4):345-52.

18. Panova T, Lleras A. Avoidance or boredom: negative mental health outcomes associated with use of Information and Communication Technologies depend on users' motivations. Comput Hum Behav. 2016;58:249-58.

19. Ward AF, Duke K, Gneezy A, Bos MW. Brain drain: the mere presence of one's own smartphone reduces available cognitive capacity. J Assoc Consum Res. 2017;2(2):140-54.

20. Chiu S-I. The relationship between life stress and smartphone addiction on Taiwanese university student: a mediation model of learning selfefficacy and social self-efficacy. Comput Hum Behav. 2014;34:49-57.

21. Darcin AE, Noyan C, Nurmedov S, Yilmaz O, Dilbaz N. Smartphone addiction in relation with social anxiety and loneliness among university students in Turkey. Eur Psychiatry. 2015;30(S1):1-1.

22. Billieux J, Maurage P, Lopez-Fernandez O, Kuss DJ, Griffiths MD. Can disordered mobile phone use be considered a behavioral addiction? An update on current evidence and a comprehensive model for future research. Curr Addict Rep. 2015;2(2):156-62.

23. Billieux J, Schimmenti A, Khazaal Y, Maurage P, Heeren A. Are we overpathologizing everyday life? A tenable blueprint for behavioral addiction research. J Behav Addict. 2015:4(3):119-23.

24. Billieux J. Problematic use of the mobile phone: a literature review and a pathways model. Curr Psychiatry Rev. 2012;8(4):299-307.

25. De-Sola Gutiérrez J, Rodríguez de Fonseca F, Rubio G. Cell-phone addiction: a review. Front Psychiatry. 2016;7:175

26. De-Sola J, Talledo H, Rubio G, de Fonseca FR. Psychological factors and alcohol use in problematic mobile phone use in the Spanish population. Front Psych. 2017;8:11.

27. Jiang Z, Zhao X. Brain behavioral systems, self-control and problematic mobile phone use: the moderating role of gender and history of use. Personality Individ Differ. 2017;106:111-6.

28. Choliz M. Mobile phone addiction: a point of issue. Addiction. 2010;105(2):373-4.

29. Jenaro C, Flores N, Gómez-Vela M, González-Gil F, Caballo C. Problematic internet and cell-phone use: psychological, behavioral, and health correlates. Addict Res Theory. 2007;15(3):309-20.

30. Lee H, Ahn H, Choi S, Choi W. The SAMS: smartphone addiction management system and verification. J Med Syst. 2014;38(1):1-10.

31. Lin YH, Chang LR, Lee YH, Tseng HW, Kuo TB, Chen SH. Development and validation of the Smartphone Addiction Inventory (SPAI). PLOS ONE. 2014;9(6):e98312 
32. Salehan M, Negahban A. Social networking on smartphones: when mobile phones become addictive. Comput Hum Behav. 2013;29(6):2632-9.

33. Panova $T$, Carbonell $X$. Is smartphone addiction really an addiction? J Behav Addict. 2018;7(2):252-9.

34. American Psychiatric Association. Diagnostic and statistical manual of mental disorders_-Fifth edition (2013)

35. Gao Y, Li A, Zhu T, Liu X, Liu X. How smartphone usage correlates with social anxiety and loneliness. PeerJ. 2016:4:e2197.

36. Chen L, Yan Z, Tang W, Yang F, Xie X, He J. Mobile phone addiction levels and negative emotions among Chinese young adults: the mediating role of interpersonal problems. Comput Hum Behav. 2016;55:856-66.

37. Lepp A, Barkley JE, Karpinski AC. The relationship between cell phone use, academic performance, anxiety, and satisfaction with life in college students. Comput Hum Behav. 2014;31:343-50.

38. Samaha M, Hawi NS. Relationships among smartphone addiction, stress, academic performance, and satisfaction with life. Comput Hum Behav. 2016:57:321-5.

39. Yang Z, Asbury K, Griffiths MD. An exploration of problematic smartphone use among Chinese university students: associations with academic anxiety, academic procrastination, self-regulation and subjective wellbeing. Int J Ment Heal Addict. 2019;17(3):596-614.

40. Ching SM, Yee A, Ramachandran V, Lim SMS, Sulaiman WAW, Foo YL, Kee Hoo F. Validation of a Malay version of the smartphone addiction scale among medical students in Malaysia. PLoS ONE. 2015;10(10):e0139337.

41. Kwon M, Kim DJ, Cho H, Yang S. The smartphone addiction scale: development and validation of a short version for adolescents. PLOS ONE. 2013;8(12):e83558.

42. Luk TT, Wang MP, Shen C, Wan A, Chau PH, Oliffe J, Viswanath K, Chan SS, Lam TH. Short version of the smartphone addiction scale in Chinese adults: psychometric properties, sociodemographic, and health behavioral correlates. J Behav Addict. 2018;7(4):1157-65.

43. De Pasquale C, Sciacca F, Hichy Z. Italian validation of smartphone addiction scale short version for adolescents and young adults (SAS-SV). Psychology. 2017;8(10):1513-8.

44. Sfendla A, Laita M, Nejjar B, Souirti Z, Touhami AAO, Senhaji M. Reliability of the Arabic smartphone addiction scale and smartphone addiction scale-short version in two different Moroccan samples. Cyberpsychol Behav Soc Netw. 2018;21(5):325-32.

45. Vintilă M, Tudorel OI, Goian C, Bărbat C. Determining the structure of smartphone addiction scale: a bifactor model analysis. Curr Psychol. pp. $1-8$.

46. Noyan CO, Darcin AE, Nurmedov S, Yilmaz O, Dilbaz N. Validity and reliability of the Turkish version of the Smartphone Addiction Scale-Short version among university students/Akilli Telefon Bagimliligi Olceginin Kisa Formunun universite ogrencilerinde Turkce gecerlilik ve guvenilirlik calismasi. Anadolu Psikiyatri Dergisi. 2015;16(S1):73-82.

47. Lopez-Fernandez O. Short version of the Smartphone addiction scale adapted to Spanish and French: towards a cross-cultural research in problematic mobile phone use. Addict Behav. 2017;64:275-80.

48. Fathalla MM. Egyptian validation of smartphone addiction scale short version for adolescents (SAS-SV). Psycho-Educ Res Rev. 2019:7-10.

49. Zhang KZ, Chen C, Lee MK. Understanding the role of motives in smartphone addiction. In: PACIS: 2014; 2014: 131.

50. Oedegaard KJ, Syrstad VE, Morken G, Akiskal HS, Fasmer OB. A study of age at onset and affective temperaments in a Norwegian sample of patients with mood disorders. J Affect Disord. 2009;118(1-3):229-33.

51. Goldsmith HH, Buss AH, Plomin R, Rothbart MK, Thomas A, Chess S, Hinde RA, McCall RB. Roundtable: what is temperament? Four approaches. Child Dev. 1987:505-529.

52. Placidi G, Signoretta S, Liguori A, Gervasi R, Maremmani I, Akiskal H. The semi-structured affective temperament interview (TEMPS-I): reliability and psychometric properties in 1010 14-26-year-old students. J Affect Disord. 1998;47(1-3):1-10.

53. Ozturk FO, Ekinci M, Ozturk O, Canan F. The relationship of affective temperament and emotional-behavioral difficulties to internet addiction in Turkish teenagers. Int Scholar Res Not 2013, 2013.

54. Cordeiro R, Figueira M. Self-esteem and affective temperament of nurses in psychiatric and mental health services. Eur Psychiatry. 2009;24(S1):1-1.
55. Vahip S, Kesebir S, Alkan M, Yazıcı O, Akiskal KK, Akiskal HS. Affective temperaments in clinically-well subjects in Turkey: initial psychometric data on the TEMPS-A. J Affect Disord. 2005;85(1-2):113-25.

56. Butt S, Phillips JG. Personality and self reported mobile phone use. Comput Hum Behav. 2008;24(2):346-60.

57. Işiklar A, Şar A, Durmuşcelebi M. An investigation of the relationship between high-school students' problematic mobile phone use and their self-esteem levels. Education. 2013;134(1):9-14.

58. Nahas M, Hlais S, Saberian C, Antoun J. Problematic smartphone use among Lebanese adults aged 18-65 years using MPPUS-10. Comput Hum Behav. 2018;87:348-53.

59. Harake W, Abou Hamde NM. Lebanon economic monitor: so when gravity Beckons, the poor don't fall. In: The World Bank (2019).

60. The World Bank. Macro Poverty Outlook for Middle East and North Africa (2020). https://www.worldbank.org/en/publication/macro-poverty-outlo ok/mpo_mena\#sec 1 .

61. El Othman R, Touma E, El Othman R, Haddad C, Hallit R, Obeid S, Salameh P, Hallit S. COVID-19 pandemic and mental health in Lebanon: a crosssectional study. Int J Psychiatry Clin Pract. 2021:1-12.

62. Matar Boumosleh J, Jaalouk D. Depression, anxiety, and smartphone addiction in university students - a cross sectional study. PLOS ONE. 2017;12(8):e0182239.

63. Bitar Z, Hallit S, Khansa W, et al. Phubbing and temperaments among young Lebanese adults: the mediating effect of self-esteem and emotional intelligence. BMC Psychol. 2021;9:87. https://doi.org/10.1186/ s40359-021-00594-7.

64. Melki IS, Beydoun HA, Khogali M, Tamim H, Yunis KA, National Collaborative Perinatal Neonatal N. Household crowding index: a correlate of socioeconomic status and inter-pregnancy spacing in an urban setting. J Epidemiol Commun Health. 2004;58(6):476-80.

65. Erfurth A, Gerlach AL, Hellweg I, Boenigk I, Michael N, Akiskal HS. Studies on a German (Munster) version of the temperament auto-questionnaire TEMPS-A: construction and validation of the briefTEMPS-M. J Affect Disord. 2005;85(1-2):53-69.

66. Rosenberg M. Rosenberg self-esteem scale (RSE). Accept Commit Therapy Meas Package. 1965;61(52):18.

67. Byrne BM. Structural equation modeling with Mplus: basic concepts, applications, and programming. (Routledge, 2013)

68. Marsh HW, Hau K-T, Wen Z. In search of golden rules: comment on hypothesis-testing approaches to setting cutoff values for fit indexes and dangers in overgeneralizing Hu and Bentler's (1999) findings. Struct Equ Model. 2004;11(3):320-41.

69. George D. SPSS for windows step by step: a simple study guide and reference, 17.0 update, 10/e. Pearson Education India; 2011

70. Mishra P, Pandey CM, Singh U, Gupta A, Sahu C, Keshri A. Descriptive statistics and normality tests for statistical data. Ann Card Anaesth. 2019;22(1):67-72.

71. Hayes AF. Introduction to mediation, moderation, and conditional process analysis: a regression-based approach (Guilford publications, 2017).

72. Elkholy H, Elhabiby M, Ibrahim I. Rates of Alexithymia and Its Association with smartphone addiction among a sample of University Students in Egypt. Front Psychiatry. 2020;11:304

73. Andrade ALM, Scatena A, Martins GDG, Pinheiro BO, Becker da Silva A Enes CC, de Oliveira WA, Kim DJ. Validation of smartphone addiction scale - Short version (SAS-SV) in Brazilian adolescents. Addict Behav. 2020;110:106540.

74. Akiskal HS. The temperamental foundations of affective disorders. Interpersonal factors in the origin and course of affective disorders 1996:3-30.

75. Kim J-H, Seo M, David P. Alleviating depression only to become problematic mobile phone users: can face-to-face communication be the antidote? Comput Hum Behav. 2015;51:440-7.

76. Kuss DJ, Kanjo E, Crook-Rumsey M, Kibowski F, Wang GY, Sumich A. problematic mobile phone use and addiction across generations: the roles of psychopathological symptoms and smartphone use. J Technol Behav Sci. 2018;3(3):141-9.

77. Chou WP, Yen CF, Liu TL. Predicting effects of psychological inflexibility/ experiential avoidance and stress coping strategies for internet addiction, significant depression, and suicidality in college students: a prospective study. Int J Environ Res Public Health. 2018;15(4). 
78. Bian M, Leung L. Linking loneliness, shyness, smartphone addiction symptoms, and patterns of smartphone use to social capital. Soc Sci Comput Rev. 2015;33(1):61-79.

79. Kim E, Koh E. Avoidant attachment and smartphone addiction in college students: the mediating effects of anxiety and self-esteem. Comput Hum Behav. 2018;84:264-71.

80. Davis RA. A cognitive-behavioral model of pathological Internet use. Comput Hum Behav. 2001;17(2):187-95.

81. Harmon-Jones E, Simon L, Greenberg J, Pyszczynski T, Solomon S, McGregor H. Terror management theory and self-esteem: evidence that increased self-esteem reduced mortality salience effects. J Pers Soc Psychol. 1997;72(1):24.

82. Yea J, Kim D. Effects of the internet uses and gratifications, flow, and dispositional orientation on the internet addiction. Korean J Consum Stud. 2003;14:45-83.

83. Joinson AN. Self-esteem, interpersonal risk, and preference for e-mail to face-to-face communication. Cyberpsychol Behav. 2004;7(4):472-8.

84. Takao M, Takahashi S, Kitamura M. Addictive personality and problematic mobile phone use. Cyberpsychol Behav. 2009;12(5):501-7.

85. Ueki H, Holzapfel C, Sakado K, Washino K, Inoue M, Ogawa N. Dimension of Typus melancholicus on Kasahara's inventory for the melancholic type personality. Psychopathology. 2004;37(2):53-8.

86. Paulhus DL. Socially desirable responding: the evolution of a construct. The role of constructs in psychological and educational measurement. 2002;49459.

87. Miotto P, De Coppi M, Frezza M, Rossi M, Preti A. Social desirability and eating disorders. A community study of an Italian school-aged sample. Acta Psychiatr Scand. 2002;105(5):372-7.

88. Evans RG. Clinical relevance of the Marlowe-Crowne Scale: a review and recommendations. J Pers Assess. 1982;46(4):415-25.
89. Rochaix D, Gaetan S, Bonnet A. Troubles alimentaires, désirabilité sociale, insatisfaction corporelle et estime de soi physique chez des étudiantes de première année. In: Annales Médico-psychologiques, revue psychiatrique: 2017: Elsevier; 2017: 363-369.

90. Kesebir S, Gungordu O, Caliskan M. İki uçlu olgularda dürtüsellik, benlik saygısı ve mizaç ilişkisi: cinsiyete göre farklılaşır mı? 2014.

91. Wang Y, Terao T, Hoaki N, Goto S, Tsuchiyama K, Iwata N, Yoshimura R, Nakamura J. Type A behavior pattern and hyperthymic temperament: possible association with bipolar IV disorder. J Affect Disord. 2011;133(1-2):22-8

92. Akiskal HS, Akiskal KK. TEMPS: temperament evaluation of Memphis, Pisa, Paris and San Diego. J Affect Disord 2005;85(1-2).

93. Kobayashi S, Terao T, Shirahama M, Hatano K, Hirakawa H, Kohno K, Shiotsuki I, Ishii N. Relationship between hyperthymic temperament, self-directedness, and self-transcendence in medical students and staff members. Psychiatry Clin Neurosci. 2019;73(5):277-83.

94. Karam EG, Itani L, Fayyad J, Hantouche E, Karam A, Mneimneh Z, Akiskal $\mathrm{H}$, Rihmer Z. Temperament and suicide: a national study. J Affect Disord. 2015;184:123-8.

95. Morales Rodríguez FM, Lozano JMG, Linares Mingorance P, Pérez-Mármol JM. Influence of smartphone use on emotional, cognitive and educational dimensions in university students. Sustainability. 2020;12(16):6646.

\section{Publisher's Note}

Springer Nature remains neutral with regard to jurisdictional claims in published maps and institutional affiliations.
Ready to submit your research? Choose BMC and benefit from:

- fast, convenient online submission

- thorough peer review by experienced researchers in your field

- rapid publication on acceptance

- support for research data, including large and complex data types

- gold Open Access which fosters wider collaboration and increased citations

- maximum visibility for your research: over 100M website views per year

At BMC, research is always in progress.

Learn more biomedcentral.com/submissions 